\title{
archOnline@JCU
}

This is the Accepted Version of a paper published in the

Sleep Health

Fatima, Yaqoot, Doi, Suhail A.R., Najman, Jake M., and Al Mamun, Abdulla (2017) Continuity of sleep problems from adolescence to young adulthood: results from a longitudinal study. Sleep Health, 3 (4). pp. 290-295 http://dx.doi.org/10.1016/j.sleh.2017.04...

(C) 2015. This manuscript version is made available under the CC-BY-NC-ND 4.0 license http://creativecommons.org/licenses/by-nc-nd/4.0/

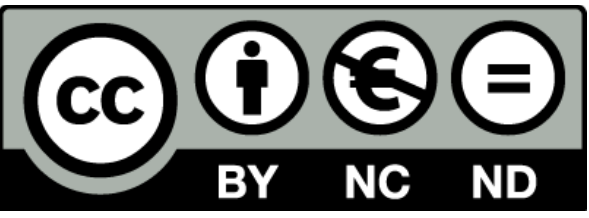




\section{Continuity of Sleep Problems from Adolescence to Young Adulthood: Results from a}

\section{Longitudinal Study}

Yaqoot Fatima, MTech ${ }^{\mathrm{a}, \mathrm{b}}$, Suhail A.R. Doi, MBBS, PhD ${ }^{\mathrm{c},}$, Jake M. Najman, PhD ${ }^{\mathrm{a}, \mathrm{d}}$, Abdullah Al Mamun, $\mathrm{PhD}^{\mathrm{a} *}$

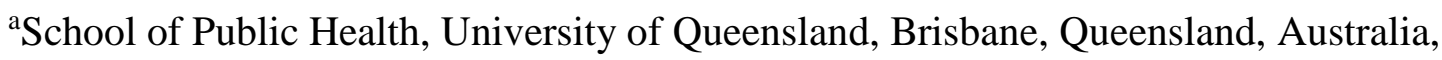

${ }^{\mathrm{b}}$ Mount Isa Centre for Rural and Remote Health, James Cook University, Queensland, Australia, 'College of Medicine, Qatar University, Doha, Qatar, ${ }^{\mathrm{d}}$ School of Social Science, University of Queensland, Brisbane, Queensland, Australia

*Correspondence: Dr. Abdullah Al Mamun, School of Public Health, University of Queensland, Herston Road, Herston, QLD 4006, Australia email: a.mamun@uq.edu.au; Tel: +61 (07) 33464689; Fax: +61 733655599

Short Title: Continuity of sleep problems

Total number of words: 2,989

Total number of references: 39

Author's contributions: YF was responsible for literature review and data analysis. AAM \& SD helped in data analysis and critically reviewed the draft of the manuscript. JN assisted in the critical review of the manuscript.

Conflict of interest: The authors declare no conflict of interests.

*This is the Accepted Version of a paper published in the journal Sleep Health Fatima Y, Doi SAR, Najman JM, Mamun AA. Prevalence and Persistence of Sleep problems from Adolescence to Young Adulthood: Results from a Birth Cohort. Sleep Health. 2017 Aug;3(4):290-295 


\begin{abstract}
Background: Considering the lack of evidence on incidence and continuity of sleep problems from adolescence to young adulthood, this study explores sleep problems incidence and their continuation rates from 14-years to 21-years.
\end{abstract}

Methods: Sleep data from the 14-years $(n=4,924)$ and 21-years $(n=3,660)$ follow-up of the MUSP cohort were used. Socio-demographic, lifestyle and psychological conditions were explored for their role in sleep problems. Modified Poisson regression with a robust error variance was used to identify predictors. Inverse probability weights were used to account for attrition.

Results: Of all subjects, $26.0 \%$ of the subjects at 14 -years and $28.3 \%$ of the subjects at 21 years reported “often” sleep problems, with $41.7 \%$ of adolescent sleep problems persisting at 21-years. Perinatal and early life maternal factors, e.g., drug abuse (IRR: 1.32, 95\%CI: 1.02-1.71), smoking, depression, and anxiety were significant predictors of adolescent sleep problems. Female gender (IRR: 2.13, 95\%CI: 1.55-2.94), advanced pubertal stages, and smoking were the important predictors of sleep problems at 21-years. Adolescent depression/anxiety supported the continuity of sleep problems (IRR: 1.21, 95\%CI: 1.051.40) while exercise was seen to exert a protective effect.

Conclusion: This study indicates high rates of sleep problems in young subjects with around half of sleep problems originating in adolescence persisting in young adulthood. Therefore, early interventions are needed to manage sleep problems in young subjects and prevent further progression to other life stages. Future studies should explore if sleep problems in young adults also persist in later life stages and identify the factors supporting the continuity of sleep problems.

*This is the Accepted Version of a paper published in the journal Sleep Health Fatima Y, Doi SAR, Najman JM, Mamun AA. Prevalence and Persistence of Sleep problems from Adolescence to Young Adulthood: Results from a Birth Cohort. Sleep Health. 2017 Aug;3(4):290-295 
Keywords: Sleep problems, persistence, young subjects, depression, gender difference

\section{Introduction}

Sleep problems in adolescents have multifactorial outcomes as these are not only linked with concurrent behavioral and mood problems but also associated with subsequent cardiovascular and cognitive issues $(1,2)$ and high persistence rates (3). Therefore, detection and management of sleep problems in adolescence present an opportunity to reduce their further temporal propagation and decreases the risk for associated health issues.

Unfortunately, unlike children or older populations, prospective assessment of sleep problems incidence and persistence are considerably unexplored from adolescence to young adulthood $(4,5)$. Since the sleep behavior and patterns for this group are different from sleep behavior in other age groups, the results from children and older population should not be extrapolated to estimate sleep problems in young subjects (6). Rather, evidence from the appropriate age group is needed to help in designing effective prevention and treatment strategies.

Among the risk factors for sleep problems, depression is a well-established factor, with many studies a bi-directional association between depression and sleep problems (7). Depressed patients are seen to exhibit alterations in sleep architecture and commonly complaint of insomnia, and people with sleep problems experience elevated symptoms of affective disorders (8). Therefore, further evidence from longitudinal studies is needed to ascertain the direction of depression-sleep problems association. Many studies also highlight the role of socio-economic status as a major risk factor for sleep problems, as people with lower SES are seen to higher rates of self-reported sleep problems and poorer subjective sleep quality (9). Along with the traditional factors, excessive electronic media exposure is also emerging as another significant risk factor associated with poor sleep in the young population (10).

*This is the Accepted Version of a paper published in the journal Sleep Health Fatima Y, Doi SAR, Najman JM, Mamun AA. Prevalence and Persistence of Sleep problems from Adolescence to Young Adulthood: Results from a Birth Cohort. Sleep Health. 2017 Aug;3(4):290-295 
Excessive electronic media exposure in children and adolescents is found to be strongly associated with later bedtime and shorter sleep duration, increase the risk of developing sleep disturbances (10)

However, there is little information on whether perinatal, and early life factors affect sleep problems in adolescence and young adults. Although few studies have explored the factors supporting the continuity of sleep problems from adolescence to young adulthood (13), they fail to provide conclusive evidence the role of significant predictors, e.g., gender $(14,15)$. It is also known that factors that predict sleep problems can be different from the factors that support the continuity of sleep problems (11). Therefore, only knowing about the predictors associated with sleep problem incidence will not be enough for sleep problem interventions, and will require information on behaviors or risk factors that support the continuity of sleep problems as well.

This exploratory study, therefore, aims to examine the incidence and continuity of sleep problems from early adolescence (14 years) to young adulthood (21 years). Based on the evidence from the existing literature and postulations of the developmental origins of health and diseases approach (16) potential psycho-sociodemographic and lifestyle risk factors will be probed for their impact on incidence and continuity of sleep problems from adolescence to young adulthood.

\section{Participants and Methods}

This study is based on the sleep problems data from the Mater-University of Queensland Study of Pregnancy (MUSP) cohort obtained from the 14 and 21 years follow-up. Data were obtained from the 7223 mothers and their offspring who participated between 1981-to-1984 (12). These mothers and their offspring have been followed up prospectively, with

*This is the Accepted Version of a paper published in the journal Sleep Health Fatima Y, Doi SAR, Najman JM, Mamun AA. Prevalence and Persistence of Sleep problems from Adolescence to Young Adulthood: Results from a Birth Cohort. Sleep Health. 2017 Aug;3(4):290-295 
assessments done when the offspring were six months and 5, 14, and 21 years of age. Written informed consent from the mothers was obtained at all data collection phases and from the young adults at the 21-year follow-up of the study. Ethics committees at the Mater Hospital and the University of Queensland approved each phase of the study. Full details of the study participants and measurements have been previously reported (12). Detailed information on each follow-up and the information collected is provided in the supplementary information $(\mathrm{S}-1)$.

\section{Sleep Problems Assessment}

At 14 years and 21 years, the offspring completed the four sleep items from the Youth Self Report (YSR) (13) and Young Adult Self Report (YASR) (14), respectively. For both time points the common questions related to sleep problems in the past six months were:

- nightmares

- $\quad$ sleep more than others during the day and/or night

- trouble sleeping

- feeling overtired

At age 14 and 21 years, the questionnaire also had one additional item "sleeps less than others” and “restless sleep,” respectively. Each question was rated as often (score=2), sometimes (score=1) or rarely/never (score=0). We developed a composite sleep scale, using sleep items that were present in YSR and YASR. Although the composite score had low internal consistency for both 14 years (Cronbach's $\alpha=0.48$ ) and 21 years data (Cronbach's $\alpha$ $=0.66)$. Nonetheless, using such a composite score is justifiable given that this approach has been used in prior research and a composite score taps multiple aspects related to sleep problems (15).

*This is the Accepted Version of a paper published in the journal Sleep Health Fatima Y, Doi SAR, Najman JM, Mamun AA. Prevalence and Persistence of Sleep problems from Adolescence to Young Adulthood: Results from a Birth Cohort. Sleep Health. 2017 Aug;3(4):290-295 
The criteria to categorize sleep problems from the composite sleep problem score was done using an approach used in a previous study which reported data from the Diagnostic Interview for Children and Adolescents (DICA) (16). If the study subject reported “often” on any of the sleep problems items, or "sometimes" on all items, it was considered as "often" occurring sleep problem. A report of "sometimes" on two to four items was considered as “sometimes” occurring sleep problems. In all other cases, sleep problems were considered as “absent.”

We did not have information on the similar sleep items at 5- and 14-years follow-up, therefore, couldn’t explore sleep problems persistence and remission from 5-years to 14years.

\section{Predictors of sleep problems incidence and continuity}

The following variables from different life stages were explored for their role in sleep problem incidence and persistence in adolescence and young adulthood.

Perinatal variables: maternal age at first clinical visit (“13-19 years”, “20-35 years” , “> 35 years”), maternal anxiety depression during the last trimester of pregnancy assessed with the Delusions-Symptoms-States Inventory (17); mothers were classified as anxious/depressed if they reported four or more of seven symptoms related to depression), maternal smoking during the last trimester of pregnancy (none, 1-9 cigarettes/day, or 10 or more cigarettes/day), maternal drinking during the last trimester of pregnancy ("abstainer" "Light drinker", "Moderate drinker", "Heavy Drinker").

Birth and early life familial and individual variables: gender, race ("White,” “Asian,” and “Aboriginal-Islander”), overactivity at six months ("Almost every day”; "Few times a week”, “Few times a month”, and “rarely/never”), duration of breastfeeding recorded at 6-months *This is the Accepted Version of a paper published in the journal Sleep Health Fatima Y, Doi SAR, Najman JM, Mamun AA. Prevalence and Persistence of Sleep problems from Adolescence to Young Adulthood: Results from a Birth Cohort. Sleep Health. 2017 Aug;3(4):290-295 
follow-up (“never”, “<4 months” and “ $\geqslant 4$ months”) "maternal satisfaction with life ("very satisfied”, “satisfied”, “dissatisfied”), maternal postnatal anxiety (“non-anxious”, anxious”) and depression (“not-depressed”, “depressed) assessed with the Delusions-Symptoms-States Inventory (17).

Childhood familial and individual variables: family income at childhood ( $\geq \$ 15600 /$ annum, $\leq \$ 15599 /$ annum, selecting the 25th percentile as the cutoff below which family income was defined as low), health at age five years (“excellent/good”, “fair”, “poor”), hyperactivity at childhood (“often”; “sometimes” “never”), “maternal satisfaction with life (“very satisfied”, “satisfied”, “dissatisfied”).

Adolescence familial and individual variables: total family income at adolescence (“ $\geq \$ 20,800 /$ annum, $\leq \$ 20,799 /$ annum)”, adolescent health (“excellent/good”, “fair”, “poor”), adolescent smoking (“No”, "Yes”), alcohol consumed in adolescence ("rarely-never", "sometimes-often"), adolescent TV hours ("<1 hour/day", "1-3 hour/day", "3-5 hour/day", ">5 hour/day"), adolescent exercise ("No-<1day/week" , "2-3 days/week", "4-5 days/week", "6-7 days/week"), body mass index category (“normal”, overweight”, “obese”) (18), pubertal development using Tanner drawings (“one \& two”, “three”, “four” , and ”five”) (19), adolescent anxiety-depression problems (top 10\% ) were assessed by using the anxietydepression sub-scales from Youth Self Report (20).

\section{Statistical Analysis}

Categorical variables were examined using the chi-squared test. An inverse probability weighted Poisson regression with a robust error variance was then fitted to the data (21), using a log-link function and a binary response outcome variable for "often” sleep problems to identify predictors of “often” sleep problems. Backward selection was used to guide the

*This is the Accepted Version of a paper published in the journal Sleep Health Fatima Y, Doi SAR, Najman JM, Mamun AA. Prevalence and Persistence of Sleep problems from Adolescence to Young Adulthood: Results from a Birth Cohort. Sleep Health. 2017 Aug;3(4):290-295 
predictor selection, which started with fitting the model with all the variables of interest, then dropping the least significant variable, so long as it is not significant at the chosen significance level. Successive re-fitting reduced models was continued, applying the same rule until all remaining variables were statistically significant.

As we had significant losses to complete follow-up at 14 years and 21-years, we accounted for this at each follow-up period by running an appropriately weighted regression (22). We did this by first computing the propensity (probability) to remain in the study separately for each time period by regressing (using logistic regression) an indicator variable on the baseline explanatory variables. The fitted model gave a predicted probability for follow-up with participant characteristics (i.e. values on the explanatory variables). Each participant at the scheduled follow-up was then given weight equal to $1 / \mathrm{p}$, where $\mathrm{p}$ is the fitted probability of participating from the logistic regression. The weighted analysis was reported, although it was not substantially different from the unweighted analysis. Measures that predicted nonmissing at 14 years and 21 years included race, gender, maternal age at childbirth, maternal education, maternal anxiety during last trimester of pregnancy, maternal smoking and drinking habits, adolescent depression/anxiety, and adolescent smoking and drinking. All analyses were done using Stata version 13, College Station, TX, USA. Significance levels were $<0.05$ unless otherwise stated.

\section{Results}

At adolescence, sleep problems information was available for a total of 4,924 (51\% male) study participants, with mean age 13.9 years ( $\mathrm{SD} \pm 0.31$ ), mostly belonging to the Caucasian race (91\%). Whereas, at 21 years follow-up sleep problems information was available for a total of 3,660 subjects ( $47 \%$ male) with mean age 20.6 years ( $S D \pm 0.86)$, and the majority

*This is the Accepted Version of a paper published in the journal Sleep Health

Fatima Y, Doi SAR, Najman JM, Mamun AA. Prevalence and Persistence of Sleep problems from Adolescence to Young Adulthood: Results from a Birth Cohort. Sleep Health. 2017 Aug;3(4):290-295 
belonging to the Caucasian race (92\%). There were 3,295 (47\% males) participants with complete information on sleep problems available at both ages.

The results of chi-squared test indicate a significant gender difference in the incidence of sleep problems (Table-1). Female subjects had a similar incidence of “often” sleep problems to males at adolescence ( 26\%) but a greater incidence in young adulthood (35\% vs. 21\%). Around a quarter of the subjects at both 14 \& 21-years reported having sleep problems “often.” Just under half (42\%) of these ‘often’ sleep problems present at 14-years persisted to 21 years. Females also had a greater persistence of “often” sleep problems (half persisted) compared to males (a third persisted) (Table 2).

At 14 years of age, perinatal and early life maternal factors e.g., drug abuse in late pregnancy (IRR: 1.32), smoking (IRR: 1.20), depression (IRR: 1.23), anxiety (IRR: 1.18), and maternal dissatisfaction with life (IRR: 1.23) were strong predictors of offspring sleep problems. Female gender was also independently predictive once other variables were accounted for in the model (IRR: 1.15, model-1; Table 3).

At 21 years of age, Aboriginal-Islander racial background (IRR: 2.25), and female gender (IRR: 2.13) were the strongest predictor of “often” sleep problems. While adolescent depression/anxiety had no significant role in predicting future sleep problems (IRR: 1.60), advanced Tanner stages (IRR: 1.56) and adolescent smoking (IRR: 1.62) predicted “often” sleep problems. Of all perinatal and early life, maternal factors only maternal anxiety in pregnancy was shown to be associated with sleep problems at 21-years (model-2, Table 3). When we looked at "persistence” vs. "remitted” from 14 to 21 years regarding the "often” sleep problems, female gender (IRR: 1.24), and adolescent depression/anxiety was found to play important roles in supporting the continuity of sleep problems (IRR 1.21). Additionally,

*This is the Accepted Version of a paper published in the journal Sleep Health Fatima Y, Doi SAR, Najman JM, Mamun AA. Prevalence and Persistence of Sleep problems from Adolescence to Young Adulthood: Results from a Birth Cohort. Sleep Health. 2017 Aug;3(4):290-295 
advanced tanner stages and adolescent smoking also supported the persistence of sleep problems, while, frequent exercising (3+times per week) was seen to reduce the continuity of “often” sleep problems (IRR: 0.80; Table-4).

\section{Discussion}

The findings of this study demonstrate a high incidence of sleep problems in adolescents and young adults, with most of the "often” sleep problems persisting in young adulthood as well. We also demonstrate that perinatal and early life maternal factors have a significant role in predicting sleep problems in adolescence, but not in young adults. Rather female gender and advanced pubertal stages are the important predictors of sleep problems in young adults, with baseline depression/anxiety supporting the continuity of sleep problems from adolescence to young adulthood. Additionally, evidence for the negative predictive role of exercise on sleep problems persistence suggests that conditions associated with an active lifestyle can decrease future incidence and progression of sleep problems in young subjects.

The results of this study concur with previous studies for the high incidence and continuity of sleep problems in young subjects $(23,24)$. However, our results for sleep problems persistence rates are slightly lower than other studies (41.7\% vs. 52\%) (24). This difference could be attributed to two facts; firstly we used a sleep problem scale based on information about four items related to sleep problems, whereas, other studies used only a single or two items to tap into sleep problems. Secondly, unlike our study, other studies relied on parental reports for adolescent sleep problems assessment (24), which are found to be not as reliable as adolescent reports (25).

Though, the existing literature has conflicting evidence for the gender difference in incidence and persistence of sleep problems in young subjects $(26,27)$ we demonstrate a significant

*This is the Accepted Version of a paper published in the journal Sleep Health Fatima Y, Doi SAR, Najman JM, Mamun AA. Prevalence and Persistence of Sleep problems from Adolescence to Young Adulthood: Results from a Birth Cohort. Sleep Health. 2017 Aug;3(4):290-295 
female predilection in both incidence and continuity of sleep problems in adolescents and young adults. Therefore, in future studies, gender-based assessment of sleep problems may help in exploring nuances in sleep problems trajectories that are otherwise undetected in the combined analysis.

Unlike adolescents, the association between depression and sleep problems is well studied for the adult population, with many studies reporting a co-occurrence of affective disorders and sleep problems in clinical and the general population (28). In line with a previous study on similar age group subjects, the findings from this study do not support the primacy of depression in predicting future sleep problems in young adults (5), though baseline depression was found to support the continuation of sleep problems in future. Thus, it seems that baseline depression does not act as a precursor for future sleep problems per se, rather helps in maintaining the continuity of existing sleep problems. It may be possible that the significant association between depression and future sleep problems seen in some studies was due to the failure to exclude subjects with baseline sleep problems or not adjusting for risk factors common to both depression and sleep problems, e.g., smoking (29). Thus, the overall effect was merely a proxy for the continuation of baseline sleep problems or other risk factors and does not seem to be driven by depression itself.

Physical activity has been shown to be associated with a reduction in the severity of various sleep problems in middle-aged and older subjects (30). However, there is a lack of conclusive evidence for the role of exercise in sleep problems for young subjects $(31,32)$. One of the reasons for inconsistent findings, as identified in a meta-analysis exploring the impact of exercise on sleep (33), could be the failure to adjust for important mediating factors. However, in our study, the protective association with exercise remained significant despite concurrent consideration of BMI and other lifestyle variables. Therefore, early exercise *This is the Accepted Version of a paper published in the journal Sleep Health Fatima Y, Doi SAR, Najman JM, Mamun AA. Prevalence and Persistence of Sleep problems from Adolescence to Young Adulthood: Results from a Birth Cohort. Sleep Health. 2017 Aug;3(4):290-295 
intervention may provide an opportunity to manage and prevent further progression of sleep problems to other life stages.

Although the impact of perinatal factors such as maternal smoking, drinking and depression/anxiety in pregnancy on emotional and behavioral issues in the offspring is well documented (34), only a few studies have explored the impact of perinatal factors on sleep in offspring (35). Results from animal models demonstrate that early experiences influence the diurnal development pattern and perhaps the associated increased exposure to glucocorticoids leads to disruption of the onset of a normal diurnal pattern in the offspring (36). Our results suggest that maternal lifestyle and depression also have a role in predicting sleep problems in the offspring and exhibit an enduring impact up to late adolescence. Therefore, intervention aiming to reduce maternal anxiety/depression and healthy lifestyle choices may help in reducing the associated factors that lead to sleep problems in offspring.

Unlike other studies, the role of socioeconomic status on sleep problem was not much evident in our study (37), it could be possibly due to high attrition rate for subjects from low socioeconomic groups in the MUSP cohort. Nonetheless, the absence of difference between the weighted and unweighted results suggests that attrition is unlikely to have substantively biased our findings. Another major limitation of this study is the use of YSR and YASR for sleep problems assessment. Although these tools are inadequate for thoroughly assessing sleep issues and disorders, the sleep items on the YSR and YASR demonstrate considerable convergent validity for examining overall sleep functioning (38), and some of the questions of these scales have good agreement with the objective assessment of sleep problems (39). Using a composite sleep problems scale is an important strength of our study and makes our results more reliable than results obtained from using a single item to explore sleep problems. Our study contributes to the evidence base for the incidence and persistence of sleep *This is the Accepted Version of a paper published in the journal Sleep Health Fatima Y, Doi SAR, Najman JM, Mamun AA. Prevalence and Persistence of Sleep problems from Adolescence to Young Adulthood: Results from a Birth Cohort. Sleep Health. 2017 Aug;3(4):290-295 
problems by utilizing information from self-report and considering the independence of predictors from different life stages to provide substantial evidence for sleep problems in young subjects.

\section{Conclusion}

A large number of young subjects in this study reported having sleep problems with most of these sleep problems found to be persisting after seven years. It seems that perinatal and early life maternal factors have an important role in adolescence sleep problems, whereas, female gender, advanced pubertal stages, and smoking predict sleep problems in young adults. Although depressive symptoms support continuity of sleep problems, they may not be the precursor for future sleep problems. The findings for the protective association with exercise indicates that promoting adolescent physical activity can be a potential intervention for sleep problems in young subjects presumably by altering direct risk factors favorably. Further longitudinal research is needed to examine the continuity of adolescence and young adulthood sleep problems in later life stages.

\section{Acknowledgements}

The Mater-University Study of Pregnancy and Its Outcomes (MUSP) was funded by the National Health and Medical Research Council (NHMRC) of Australia. A.A.M. is supported by the National Health and Medical Research Council (NHMRC) Career Development Awards (ID 519756).

1. Cappuccio FP, Cooper D, D'Elia L, Strazzullo P, Miller MA. Sleep duration predicts cardiovascular outcomes: a systematic review and meta-analysis of prospective studies. Eur Heart J. 2011; 32:1484-92

2. Sadeh A, Gruber R, Raviv A. Sleep, neurobehavioral functioning, and behavior problems in school-age children. Child Dev. 2002; 73:405-17

*This is the Accepted Version of a paper published in the journal Sleep Health Fatima Y, Doi SAR, Najman JM, Mamun AA. Prevalence and Persistence of Sleep problems from Adolescence to Young Adulthood: Results from a Birth Cohort. Sleep Health. 2017 Aug;3(4):290-295 
3. Morphy H, Dunn KM, Lewis M, Boardman HF, Croft PR. Epidemiology of insomnia: a longitudinal study in a UK population. Sleep. 2007; 30:274-80

4. Pieters S, Burk W, Van der Vorst H, Dahl R, Wiers R, Engels RME. Prospective Relationships Between Sleep Problems and Substance Use, Internalizing and Externalizing Problems. J Youth Adolesc. 2015; 44:379-88

5. Dregan A, Armstrong D. Adolescence sleep disturbances as predictors of adulthood sleep disturbances--a cohort study. J Adolesc Health. 2010; 46:482-7

6. Becker SP, Langberg JM, Byars KC. Advancing a biopsychosocial and contextual model of sleep in adolescence: a review and introduction to the special issue. J Youth Adolesc. 2015; 44:239-70

7. Adams SK, Daly JF, Williford DN. Adolescent sleep and cellular phone use: recent trends and implications for research. Health Serv Insights. 2013; 6:99-103

8. Calamaro CJ, Mason TB, Ratcliffe SJ. Adolescents living the 24/7 lifestyle: effects of caffeine and technology on sleep duration and daytime functioning. Pediatrics. 2009; 123:e1005-10

9. Patten CA, Choi WS, Gillin JC, Pierce JP. Depressive symptoms and cigarette smoking predict development and persistence of sleep problems in US adolescents. Pediatrics. 2000; 106:E23

10. Luo C, Zhang J, Pan J. One-year course and effects of insomnia in rural Chinese adolescents. Sleep. 2013; 36:377-84

11. Roberts RE, Roberts CR, Chan W. Persistence and Change in Symptoms of Insomnia among Adolescents. Sleep. 2008; 31:177-84

12. Najman JM, Bor W, O'Callaghan M, Williams GM, Aird R, Shuttlewood G. Cohort Profile: The Mater-University of Queensland Study of Pregnancy (MUSP). Int J Epidemiol. 2005; 34:992-7

13. Achenbach T. Manual for the Child Behavior Checklist/4 - 18 and 1991 Profile.

Burlington: VT: University of Vermont Department of Psychiatry.; 1991

14. Achenbach TM. Manual for the Young Adult Self-Report and Young Adult Behaviour Checklist. VT: University of Vermont, Department of Psychiatry.: Burlington; 1997

15. Gregory AM, Van der Ende J, Willis TA, Verhulst FC. PArent-reported sleep problems during development and self-reported anxiety/depression, attention problems, and aggressive behavior later in life. Arch Pediatr Adolesc Med. 2008; 162:330-5

16. Stoleru S, Nottelmann ED, Belmont B, Ronsaville D. Sleep problems in children of affectively ill mothers. J Child Psychol Psychiatry. 1997; 38:831-41

17. Foulds GA, Bedford A. Hierarchy of classes of personal illness. Psychol Med. 1975; 5:181-92

18. Cole TJ, Bellizzi MC, Flegal KM, Dietz WH. Establishing a standard definition for child overweight and obesity worldwide: international survey. BMJ. 2000; 320:1240-

19. Schmitz KE, Hovell MF, Nichols JF, Irvin VL, Keating K, Simon GM, et al. A Validation Study of Early Adolescents' Pubertal Self-Assessments. J Early Adolescence. 2004; 24:357-84

20. Achenbach TM. Manual for the Youth Self Report and 1991 Profile. Burlington:

VT: Department of Psychiatry, University of Vermont.; 1991b

21. Zou G. A modified poisson regression approach to prospective studies with binary data. Am J Epidemiol. 2004; 159:702-6

*This is the Accepted Version of a paper published in the journal Sleep Health

Fatima Y, Doi SAR, Najman JM, Mamun AA. Prevalence and Persistence of Sleep problems from Adolescence to Young Adulthood: Results from a Birth Cohort. Sleep Health. 2017 Aug;3(4):290-295 
22. Seaman SR, White IR. Review of inverse probability weighting for dealing with missing data. Stat Methods Med Res. 2013; 22:278-95

23. Roberts RE, Roberts CR, Chan W. Persistence and change in symptoms of insomnia among adolescents. Sleep. 2008; 31:177-84

24. Dregan A, Armstrong D. Adolescence sleep disturbances as predictors of adulthood sleep disturbances--a cohort study. The Journal of adolescent health : official publication of the Society for Adolescent Medicine. 2010; 46:482-7

25. Fatima Y, Doi SA, O'Callaghan M, Williams G, Najman JM, Mamun AA. Parent and adolescent reports in assessing adolescent sleep problems: Results from a large population study. Acta paediatrica (Oslo, Norway : 1992). 2016;

26. Lazaratou H, Dikeos D, Anagnostopoulos D, Sbokou O, Soldatos C. Sleep problems in adolescence A study of senior high school students in Greece. Eur Child Adolesc Psychiatry. 2005; 14:237-43

27. Morrison DN, McGee R, Stanton WR. Sleep problems in adolescence. J Am Acad Child Adolesc Psychiatry. 1992; 31:94-9

28. Ohayon MM, Caulet M, Lemoine P. Comorbidity of mental and insomnia disorders in the general population. Compr Psychiatry. 1998; 39:185-97

29. Hayley AC, Skogen JC, Sivertsen B, Wold B, Berk M, Pasco JA, et al. Symptoms of Depression and Difficulty Initiating Sleep from Early Adolescence to Early Adulthood: A Longitudinal Study. Sleep. 2015; 38:1599-606

30. Reid KJ, Baron KG, Lu B, Naylor E, Wolfe L, Zee PC. Aerobic exercise improves self-reported sleep and quality of life in older adults with insomnia. Sleep Med. 2010; 11:934-40

31. Meintjes AF, Driver HS, Shapiro CM. Improved physical fitness failed to alter the EEG patterns of sleep in young women. Eur J Appl Physiol Occup Physiol. 1989; 59:1237

32. Awad KM, Drescher AA, Malhotra A, Quan SF. Effects of exercise and nutritional intake on sleep architecture in adolescents. Sleep Breath. 2013; 17:117-24

33. Youngstedt SD, O'Connor PJ, Dishman RK. The effects of acute exercise on sleep: a quantitative synthesis. Sleep. 1997; 20:203-14

34. Van den Bergh BR, Mennes M, Oosterlaan J, Stevens V, Stiers P, Marcoen A, et al. High antenatal maternal anxiety is related to impulsivity during performance on cognitive tasks in 14- and 15-year-olds. Neurosci Biobehav Rev. 2005; 29:259-69

35. O'Connor TG, Caprariello P, Blackmore ER, Gregory AM, Glover V, Fleming P, et al. Prenatal Mood Disturbance Predicts Sleep Problems in Infancy and Toddlerhood. Early Hum Dev. 2007; 83:451-8

36. Gitau R, Cameron A, Fisk NM, Glover V. Fetal exposure to maternal cortisol. Lancet. 1998; 352:707-8

37. Song Y, Ancoli-Israel S, Lewis CE, Redline S, Harrison SL, Stone KL. The association of race/ethnicity with objectively measured sleep characteristics in older men. Behav Sleep Med. 2011; 10:54-69

38. Becker SP, Ramsey RR, Byars KC. Convergent validity of the Child Behavior Checklist sleep items with validated sleep measures and sleep disorder diagnoses in children and adolescents referred to a sleep disorders center. Sleep Med. 2015; 16:7986

*This is the Accepted Version of a paper published in the journal Sleep Health

Fatima Y, Doi SAR, Najman JM, Mamun AA. Prevalence and Persistence of Sleep problems from Adolescence to Young Adulthood: Results from a Birth Cohort. Sleep Health. 2017 Aug;3(4):290-295 
39. Gregory AM, Cousins JC, Forbes EE, Trubnick L, Ryan ND, Axelson DA, et al. Sleep items in the child behavior checklist: a comparison with sleep diaries, actigraphy, and polysomnography. J Am Acad Child Adolesc Psychiatry. 2011; 50:499-507

*This is the Accepted Version of a paper published in the journal Sleep Health Fatima Y, Doi SAR, Najman JM, Mamun AA. Prevalence and Persistence of Sleep problems from Adolescence to Young Adulthood: Results from a Birth Cohort. Sleep Health. 2017 Aug;3(4):290-295 
Table 1: Prevalence and persistence of sleep problems from adolescence to young adulthood

\begin{tabular}{|c|c|c|c|c|c|c|c|}
\hline \multirow[b]{2}{*}{ Sleep Problems } & \multicolumn{3}{|c|}{ Males } & \multicolumn{3}{|c|}{ Females } & \multirow[b]{2}{*}{ p-value* } \\
\hline & $\begin{array}{l}\text { Often } \\
\text { N (\%) }\end{array}$ & $\begin{array}{c}\text { Sometimes } \\
\text { N (\%) }\end{array}$ & $\begin{array}{c}\text { Absent } \\
\text { N (\%) }\end{array}$ & $\begin{array}{l}\text { Often } \\
\text { N (\%) }\end{array}$ & $\begin{array}{c}\text { Sometimes } \\
\text { N (\%) }\end{array}$ & $\begin{array}{l}\text { Absent } \\
\text { N (\%) }\end{array}$ & \\
\hline \multicolumn{8}{|c|}{ Prevalence of sleep problems at 14-years and at 21-years } \\
\hline Age 14 years & $648(25.8)$ & $914(36.4)$ & 952 (37.8) & $630(26.1)$ & $971(40.3)$ & 809 (33.6) & \multirow{2}{*}{$<0.001$} \\
\hline Age 21 years & $358(20.8)$ & $612(35.6)$ & $751(43.6)$ & $676(34.9)$ & 812 (41.9) & $451(23.2)$ & \\
\hline \multicolumn{8}{|l|}{ *p-value: Chi-square test } \\
\hline \multicolumn{8}{|c|}{ Table 2: Changes in “often” sleep problems from 14 to 21 years for male and female subjects } \\
\hline \multirow{3}{*}{$\begin{array}{c}\text { Sleep Problems data at } \\
\text { 14-years }\end{array}$} & \multicolumn{3}{|c|}{ Males } & & \multicolumn{3}{|c|}{ Females } \\
\hline & \multirow{2}{*}{$\begin{array}{c}\text { Often sleep } \\
\text { problems at } \\
\text { 14- years } \\
\text { N (\%) } \\
\end{array}$} & \multicolumn{3}{|c|}{$\begin{array}{c}\text { Trajectories of often sleep } \\
\text { problems from 14-yrs to 21-yrs }\end{array}$} & \multirow{2}{*}{$\begin{array}{c}\text { Often sleep } \\
\text { problems at } \\
\text { 14- years } \\
\text { N (\%) }\end{array}$} & \multicolumn{2}{|c|}{$\begin{array}{c}\text { Trajectories of often sleep problems } \\
\text { from 14-yrs to 21-yrs }\end{array}$} \\
\hline & & $\begin{array}{l}\text { Persistent at 21- } \\
\text { yrs N (\%) }\end{array}$ & \multicolumn{2}{|c|}{$\begin{array}{l}\text { Remitted at } \\
\text { 21-yrs N (\%) }\end{array}$} & & $\begin{array}{c}\text { Persistent at 21- } \\
\text { yrsN (\%) }\end{array}$ & $\begin{array}{c}\text { Remitted at 21- } \\
\text { yrsN (\%) }\end{array}$ \\
\hline Non-missing data at 21-years & $392(60.6)$ & \multirow[t]{3}{*}{$135(34.4)$} & \multicolumn{2}{|c|}{$257(65.6)$} & \multirow{3}{*}{$\begin{array}{l}474(75.2) \\
156(24.8) \\
630(100) \\
\end{array}$} & $226(47.7)$ & $248(52.3)$ \\
\hline Missing data at 21-years & $256(39.4)$ & & & & & & \\
\hline Total & $648(100)$ & & & & & & \\
\hline \multirow{2}{*}{$\begin{array}{c}\text { Sleep Problems data at } \\
\text { 21-years }\end{array}$} & \multirow{2}{*}{$\begin{array}{c}\text { Often sleep } \\
\text { problems at } \\
21-\text { years } \\
\text { N (\%) }\end{array}$} & \multicolumn{3}{|c|}{$\begin{array}{c}\text { Reports of often sleep problems } \\
\text { at 21-yrs }\end{array}$} & \multirow{2}{*}{$\begin{array}{l}\text { Often sleep } \\
\text { problems at } \\
21 \text { - years } \\
\text { N (\%) }\end{array}$} & \multicolumn{2}{|c|}{$\begin{array}{c}\text { Reports of often sleep problems at } \\
21-y r s\end{array}$} \\
\hline & & $\begin{array}{c}\text { Persisting } \\
\text { from 14-yrs } \\
\text { N (\%) } \\
\end{array}$ & $\begin{array}{r}\text { Incident } \\
\mathbf{N}(\end{array}$ & $\begin{array}{l}\text { t 21-yrs } \\
\text { o) }\end{array}$ & & $\begin{array}{c}\text { Persisting from } \\
\text { 14-yrs } \\
\text { N (\%) } \\
\end{array}$ & $\begin{array}{c}\text { Incident at 21-yrs } \\
\mathrm{N}(\%)\end{array}$ \\
\hline Non-missing data at 14 -years & 318 (89.9) & $135(42.5)$ & 183( & 7.5) & $616(91.1)$ & $226(36.7)$ & $390(63.3)$ \\
\hline Missing data at 14 -years & $40(11.1)$ & & & & $60(8.9)$ & & \\
\hline Total & $358(100)$ & & & & $676(100)$ & & \\
\hline
\end{tabular}

*This is the Accepted Version of a paper published in the journal Sleep Health

Fatima Y, Doi SAR, Najman JM, Mamun AA. Prevalence and Persistence of Sleep problems from Adolescence to Young Adulthood: Results from a Birth Cohort. Sleep Health. 2017 Aug;3(4):290-295 
Table 3: Predictors associated with “often” sleep problems prevalence at 14 years and 21 years

\begin{tabular}{|c|c|c|c|c|}
\hline \multirow[t]{2}{*}{ Predictors } & \multicolumn{2}{|c|}{ Sleep problems at 14-years (Model-1) } & \multicolumn{2}{|c|}{ Sleep problems at 21-years (Model-2) } \\
\hline & IRR & $95 \% \mathrm{CI}$ & IRR & $95 \% \mathrm{CI}$ \\
\hline Females & 1.15 & $1.04-1.27$ & 2.13 & $1.55-2.94$ \\
\hline Aboriginal-Islander race & & & 2.25 & $1.36-3.72$ \\
\hline Maternal drug abuse in late pregnancy & 1.32 & $1.02-1.71$ & & \\
\hline Maternal depression in late pregnancy & 1.23 & $1.02-1.48$ & & \\
\hline Maternal pre-pregnancy BMI category (normal weight) & 0.86 & $0.77-0.96$ & & \\
\hline Maternal smoking in last trimester of pregnancy (heavy) & 1.20 & $1.03-1.39$ & & \\
\hline Maternal anxiety in late pregnancy & 1.18 & $1.02-1.37$ & 1.56 & $1.02-2.36$ \\
\hline Hyperactivity at age 5 -years (often) & 1.36 & $1.11-1.66$ & & \\
\hline Hyperactivity at age 5-years (sometimes) & 1.21 & $1.09-1.34$ & & \\
\hline Adolescent depression/anxiety at 14-years & & & 1.60 & $0.55-4.65$ \\
\hline Smoking at age 14-years & & & 1.62 & $1.06-2.45$ \\
\hline Tanner stage 3 & & & 1.56 & $1.15-2.12$ \\
\hline
\end{tabular}

Predictors entered via backward selection ( $\mathrm{pr}=0.10)$, area under curve for the model-1: 0.61, model-2: 0.68, IRR: Incidence Rate Ratio

*This is the Accepted Version of a paper published in the journal Sleep Health

Fatima Y, Doi SAR, Najman JM, Mamun AA. Prevalence and Persistence of Sleep problems from Adolescence to Young Adulthood: Results from a Birth Cohort. Sleep Health. 2017 Aug;3(4):290-295 
Reference category: race: Caucasian, maternal pre-pregnancy BMI: low 10\%, maternal drug abuse: no, maternal anxiety: non-anxious, maternal depression: non-depressed, maternal smoking: none, maternal satisfaction with life: very satisfied, overactivity at age 5-years: never, adolescent depression/anxiety: non-cases, Tanner stage: one \& two, smoking at age 14-years: no

Table 4: Predictors associated with the changes in "often” sleep problems (persisted vs. remitted) from 14 years to 21 years

\begin{tabular}{lcc}
\hline \multirow{2}{*}{ Predictors } & \multicolumn{2}{c}{$\begin{array}{c}\text { Persistent sleep problems from } \\
\text { 14 years to 21-years }\end{array}$} \\
\cline { 2 - 3 } & \multicolumn{1}{c}{ IRR } & $\mathbf{9 5 \% \mathbf { C I }}$ \\
\hline Females & 1.24 & $1.06-1.46$ \\
Adolescent depression/anxiety at 14-years & 1.21 & $1.05-1.40$ \\
Smoking at age 14-years & 1.23 & $1.06-1.42$ \\
Tanner stage 3 & 1.15 & $0.98-1.35$ \\
Tanner stage 5 & 1.20 & $1.00-1.43$ \\
Exercise 3+ times/week at 14-years & 0.80 & $0.63-1.01$ \\
Exercise 2-3 times/week at 14-years & 0.75 & $0.60-0.95$ \\
\hline
\end{tabular}

Predictors entered via backward selection ( $\mathrm{pr}=0.10$ ), area under curve for the model: 0.71

IRR: Incidence Rate Ratio

Reference category: adolescent depression/anxiety: non-cases, Tanner stage: one \& two, exercise: none, smoking at age 14-years: no

*This is the Accepted Version of a paper published in the journal Sleep Health

Fatima Y, Doi SAR, Najman JM, Mamun AA. Prevalence and Persistence of Sleep problems from Adolescence to Young Adulthood: Results from a Birth Cohort. Sleep Health. 2017 Aug;3(4):290-295 